\title{
OPEN Incidence, demographics, and survival of patients with primary pituitary tumors: a SEER database study in 2004-2016
}

\author{
Cheng Chen ${ }^{1,4}$, Yu Hu ${ }^{1,4}$, Liang Lyu ${ }^{1,2}$, Senlin Yin ${ }^{1}$, Yang Yu ${ }^{1}$, Shu Jiang ${ }^{1,3}$ \& Peizhi Zhou ${ }^{1,3 凶}$
}

Comprehensive investigations on the incidence and prognosis of pituitary tumors are still lacking. The present study aims to summarize the incidence, demographics, and survival outcome of pituitary adenoma on a population-based level. This study includes all pituitary adenomas reported in the Surveillance, Epidemiology, and End Results (SEER) database from 2004 to 2016 in the United States. Extensive clinical and demographic characteristics were extracted and submitted to group comparisons. The standardized incidence rate was calculated and stratified by year at diagnosis, age/sex and age/treatment groups. The Kaplan-Meier analysis and multivariable regressions were performed to identify the factors associated with overall survival. A total of 47,180 pituitary tumors were identified, including 47,030 typical adenomas, 111 uncertain behavior pituitary adenomas, and 39 pituitary carcinomas. The overall standardized incidence rate was 4.8 cases per 100,000 personyears and the annual incidence rate continually trended upwards, with a peak seen in 2015 . We noticed a bimodal age-related distribution in females and a unimodal distribution in males. In the multivariate regression analysis, the factors associated with prolonged survival included typical adenoma, younger age, and smaller tumor size. Whereas, black and male patients had worse overall survival. Our study provides a reliable estimate on the incidence of pituitary adenoma and confirms that the annual standardized incidence rate is increasing. Pituitary adenomas have a satisfactory long-term prognosis and age, tumor size, and tumor subtypes are related to overall survival. Though statistically significant, our inferential findings should be constrained within the limitations of SEER database.

With a prevalence of approximately $1 / 1000$ in case-finding studies, pituitary tumors are more frequent than thought ${ }^{1}$. Although the etiology of pituitary tumors covers a wide range of pathologies, most of them are typical benign adenomas. Despite their generally benign nature, these tumors can lead to considerable morbidity and elevated mortality ${ }^{2-6}$, which pose a significant burden to health care resources. A comprehensive investigation regarding the incidence and long-term prognosis of primary pituitary adenoma is crucial to better understand the natural course of the disease and lend support to the medical decision-making process. However, robust population-based estimates relating to the incidence and overall survival of pituitary tumors are still lacking and the existing data of epidemiological characteristics are discordant ${ }^{6-10}$.

On January 1, 2004, cancer registries in the Surveillance, Epidemiology, and End Results (SEER) project began to identify and abstract benign and borderline tumors of the central nervous system ${ }^{11}$. The collection of benign brain tumors provided us with enormous opportunities for disease epidemiology analysis. Therefore, our present study aims to summarize the incidence rate, demographics, and survival outcome of all primary pituitary tumors diagnosed between 2004 and 2016 in the SEER database.

\footnotetext{
${ }^{1}$ Department of Neurosurgery, West China Hospital of Sichuan University, No. 37, Guoxue Alley, Chengdu 610041, Sichuan Province, People's Republic of China. ${ }^{2}$ State Key Laboratory of Biotherapy, Sichuan University, Chengdu, Sichuan Province, People's Republic of China. ${ }^{3}$ Pituitary Adenoma Multidisciplinary Center, West China Hospital of Sichuan University, Chengdu, Sichuan Province, People's Republic of China. ${ }^{4}$ These authors contributed equally: Cheng Chen and Yu Hu. ${ }^{\square}$ email: peizhizhou@126.com
} 


\section{Materials and methods}

Patient selection. The cohort utilized in the current research was extracted from the SEER 18 registries customized database (with additional treatment fields), which covers approximately $27.8 \%$ of the US population and with an appropriate representation of most ethnicities in the United States ${ }^{12}$. After signing the Research Data Agreement chart and being authorized by SEER program ${ }^{13}$, the username and password were assigned for SEER ${ }^{\star}$ Stat software login. In the SEER 18 registries dataset, we included patients with primary labeled site pituitary gland (C75.1 only) tumors and the selection criteria were not limited to malignant behavior. Patients with multiple primary sites, non-pituitary adenoma diagnosis, death certificate reporting sources, or diagnosed before 2004 were excluded, leaving 47,180 patients qualified for the final statistical analysis. Only the tumors with documented metastasis were defined as pituitary carcinomas (PCs) and the classification procedures were abided by the SEER Collaborative Stage Metastasis at Distance principles ${ }^{14}$. The tumors with malignant or borderline histologic behavior but without distant metastasis were classified as uncertain behavior pituitary adenomas (UPAs).

Variables classification. Demographic information was extracted and stratified by age, gender, race, insurance, marital status, urbanization, purchased/referred care delivery area (PRCDA) regions, tumor size, Third Edition of the International Classification of Diseases for Oncology (ICD-O-3), treatment modalities, survival months, and vital status. Age at diagnosis was categorized with a five years interval from birth to $85+$ years. The standardized incidence rate was calculated per 100,000 person-years by dividing the number of patients by the observation years and the corresponding population. The general US population and age-adjusted reference population were accessed through the SEER standard population dataset, which was originally obtained from the US Census Bureau's Population Projections Program ${ }^{15}$. Subtotal resection (STR) included local tumor destruction (surgical code 10), local tumor excision (code 20), excisional biopsy (code 27), and partial removal of the primary site (code 30). Gross total resection (GTR) included total surgical removal of the primary site and radical surgery (surgical code 40 and 60, respectively).

Survival parameters. The survival months and vital status are available in the SEER database and those cases without active follow-up were excluded from survival analysis. The survival proportion curves included tumor subtypes, age groups ( $\leq 18$ years, $19-64$ years, and $\geq 65$ years), and tumor size (cutoff at the median value: $\leq 16 \mathrm{~mm}$ and $>16 \mathrm{~mm}$ ) and they were obtained using the Kaplan-Meier method and compared by logrank test. The relevant covariates' effect on overall survival outcome was submitted to multivariable regression models.

Statistical analysis. Data were extracted with SEER ${ }^{\star}$ Stat statistical software (Version 8.3.8, National Cancer Institute, Maryland, USA). We compared the RC list categorical variables with Person's Chi-squared test and the normally distributed continued variables with independent sample ANOVA. When the data showed an abnormal distribution or heterogeneity of variance, the Kruskal-Willis H test was adopted for nonparametric comparison. Cox proportional hazard regression and binary logistic regression were used for multivariate analysis. Two-sided $P$ values $<0.05$ were considered to be statistically significant. We used SPSS program (Version 25.0, IBM Corp., Armonk, New York, USA) and Prism 8 (GraphPad Software Inc., San Diego, CA, USA) to analyze data and generate illustrations. All the data and statistical results were independently cross-checked by two authors (C.C.) and (Y.H.).

Ethics approval. As data acquisition in the SEER database is de-identified and poses no risk for individual participants, our study was exempt from review by the ethics committee of West China Hospital.

\section{Results}

Demographics. From 2004 to 2016, a total of 47,180 pituitary tumor patients with a mean follow-up of 5.1 years were reported in the SEER 18 registries database. Stratified by biological behavior subtypes, 47,030 tumors were classified as typical adenomas, 111 as UPAs, and 39 as PCs. The demographic and clinical characteristics univariate comparisons are presented in Table 1. Approximately three-quarters of the patients were Caucasian and $73 \%$ were aged between 19 and 64 years. Among the 4,242 (9\%) other race patients, $80 \%$ were Asiatic ethnicity. Typical adenoma patients were younger at diagnosis compared to UPA patients $(49.4 \pm 18.4$ years vs. $55.4 \pm 16.7$ years, $P=0.001$ ). PCs accounted for only $0.08 \%$ of all pituitary tumors and were more likely to be found in males than typical adenomas $(67 \%$ vs. $44 \%, P=0.004)$. Both UPAs and PCs were significantly larger than typical adenomas in terms of tumor size $(P<0.001)$.

Most patients $(87 \%)$ had a not specified pituitary adenoma $(8272 / 0)$ histology, while pituitary carcinoma $(8272 / 3,85 \%)$ was the most frequent type in ICD-O-3 malignant designation (Table 2). Overall, 21,340 patients (45\%) underwent surgical resection and most of them $(94 \%)$ received surgery as their sole treatment modality. Additionally, 1676 patients (4\%) received radiation therapy, and beam radiation (99\%) was the most frequently utilized method. Also, irradiation was more likely to be performed on patients with UPAs and PCs than typical adenomas $(P<0.001)$ (Table 3$)$. It should be noted that UPAs and PCs remained highly consistent in terms of clinical and demographic characteristics, and no significant differences were observed between these two groups.

Incidence. The overall standardized incidence rate was 4.8 cases per 100,000 person-years over 13 years of surveillance. Most patients were female in gender (56\%), and the incidence rate was higher in female patients than male (5.3 cases per 100,000 person-years vs. 4.3 cases per 100,000 person-years). For the whole population, 


\begin{tabular}{|c|c|c|c|c|}
\hline Variables $^{\mathrm{a}}$ & Typical adenomas & UPAs & PCs & $P$ \\
\hline Total patients & 47,030 & 111 & 39 & \\
\hline Age at diagnosis, mean $\pm S D$, year & $49.4 \pm 18.4$ & $55.4 \pm 16.7$ & $50.9 \pm 18.6$ & $0.001^{\star *}$ \\
\hline \multicolumn{4}{|l|}{ Age groups, year } & 0.181 \\
\hline$\leq 18$ & $1821(4)$ & $2(2)$ & $3(8)$ & \\
\hline $19-64$ & $34,165(73)$ & $75(68)$ & $25(64)$ & \\
\hline$\geq 65$ & $11,044(23)$ & $34(30)$ & $11(28)$ & \\
\hline \multicolumn{4}{|l|}{ Sex } & $0.004^{\star}$ \\
\hline Male & $20,583(44)$ & $54(49)$ & $26(67)$ & \\
\hline Female & $26,447(56)$ & $57(51)$ & $13(33)$ & \\
\hline M:F Ratio & $1: 1.3$ & $1: 1.06$ & $2: 1$ & \\
\hline \multicolumn{4}{|l|}{ Race } & $0.010^{\star *}$ \\
\hline White & $33,313(71)$ & $67(60)$ & $28(72)$ & \\
\hline Black & $8417(18)$ & $32(29)$ & $9(23)$ & \\
\hline Other & $4228(9)$ & $12(11)$ & $2(5)$ & \\
\hline Unknown & $1072(2)$ & 0 & 0 & \\
\hline \multicolumn{4}{|l|}{ Insurance $^{b}$} & 0.775 \\
\hline Insured & $35,553(91)$ & $71(90)$ & & $28(88)$ \\
\hline Uninsured & $1617(4)$ & $2(3)$ & & $1(3)$ \\
\hline Unknown & $1782(5)$ & $6(8)$ & & $3(9)$ \\
\hline \multicolumn{4}{|l|}{ Marital status } & 0.581 \\
\hline Married & $30,682(65)$ & $73(66)$ & $22(56)$ & \\
\hline Unmarried & $12,750(27)$ & $32(29)$ & $13(33)$ & \\
\hline Unknown & $3598(8)$ & $6(5)$ & $4(10)$ & \\
\hline \multicolumn{4}{|l|}{ Urbanization } & 0.309 \\
\hline Urban & $42,601(91)$ & $97(87)$ & 37 (95) & \\
\hline Rural & $4296(9)$ & $14(13)$ & $2(5)$ & \\
\hline Unknown & $133(0.2)$ & 0 & 0 & \\
\hline \multicolumn{4}{|l|}{ Region } & $<0.001^{* *}$ \\
\hline Pacific coast & $23,428(50)$ & 37 (33) & $13(33)$ & \\
\hline East & $17,083(36)$ & $63(57)$ & $20(51)$ & \\
\hline Other & $6519(14)$ & $11(10)$ & $6(15)$ & \\
\hline Tumor size ${ }^{\mathrm{c}}$, mean $\pm \mathrm{SD}, \mathrm{cm}$ & $18.1 \pm 13.2$ & $29.7 \pm 18.7$ & $27.6 \pm 13.4$ & $<0.001^{* * *}$ \\
\hline
\end{tabular}

Table 1. Demographic and clinical characteristics of patients included in the present study. UPAs Uncertain behavior pituitary adenomas, PCs Pituitary carcinomas. ${ }^{a}$ Data were presented in numbers and percentages unless noted otherwise, unknown status was no included in statistical comparisons. ${ }^{b}$ For cases registered 2007 and onward. ${ }^{c}$ Only cases with exact tumor size recorded were calculated $(\mathrm{n}=36,732) .{ }^{\star} P$ value for difference between PCs and typical adenomas, ${ }^{* *} P$ value for difference between UPAs and typical adenomas, ${ }^{* *} P$ value for difference between UPAs + PCs and typical adenomas.

the annual incidence rate continually trended upwards, with a peak seen in 2015 (5.8 cases per 100,000 personyears) (Fig. 1a). When adjusted for corresponding age groups and sex, a bimodal age-related distribution was observed in female patients, with a first peak seen in adults aged 25-34 years and a second peak in the elderly aged 60-69 years. A unimodal age-related distribution was seen in males and the incidence rate was notably higher in the sixth decade of lifespan (Fig. 1b). When compared the treatment modalities in the incidence rate of pituitary tumors, patients aged 45-74 years were more likely to be treated more actively, otherwise they were probably not to receive any treatment (Fig. 1c).

Survival. A total of 46,121 active follow-up patients contributed to 240,459 observation years and the overall survival rates at 3,5, and 10 years were $94.3 \%, 91.3 \%$, and $83.1 \%$, respectively. The Kaplan-Meier curves, which compared the difference in survival rate by tumor subtypes, age groups, and tumor size, showed a statistically significant survival advantage for typical adenoma patients compared to UPA and PC patients (Fig. 2a). Also, older age at diagnosis and larger tumor size were associated with significantly worse survival compared to younger patients and patients with relatively smaller tumor sizes (Fig. 2b,c). Table 4 provides the results of multivariate regression analysis for the demographic and clinical variables associated with survival outcome. Females displayed significantly better survival than men with a hazard ratio (HR) of 1.275 (95\%CI, 1.203-1.352, $P<0.001)$ and odds ratio (OR) of 1.326 (95\%CI, 1.241-1.418, $P<0.001)$. Black patients showed worse survival in both regression models compared to white patients (HR, 1.269 (95\%CI 1.185-1.360), $P<0.001$; OR, 1.339 (95\%CI 1.235-1.452), $P<0.001)$, while other ethnic patients had the best overall survival (HR, 0.689 (95\%CI 0.615-0.771), $P<0.001$; OR, 0.627 (95\%CI 0.554-0.710), $P<0.001$ ). Patients who received radiation treatment 


\begin{tabular}{|c|c|}
\hline Histologic behaviors and codes & n (\%) \\
\hline \multicolumn{2}{|l|}{ Benign behavior } \\
\hline 8272/0: Pituitary adenoma, NOS & $41,009(87)$ \\
\hline 8140/0: Adenoma, NOS & $3681(8)$ \\
\hline 8271/0: Prolactinoma & $1984(4)$ \\
\hline Others $^{\mathrm{a}}$ & $383(1)$ \\
\hline \multicolumn{2}{|l|}{ Borderline behavior } \\
\hline 8272/1: Pituitary adenoma, borderline malignancy & $13(68)$ \\
\hline 8140/1: Atypical adenoma & $5(26)$ \\
\hline 8270/1: Chromophobe adenoma, borderline & $1(5)$ \\
\hline \multicolumn{2}{|l|}{ Malignant behavior } \\
\hline 8272/3: Pituitary carcinoma, NOS & $88(85)$ \\
\hline 8140/3: Adenocarcinoma, NOS & $7(7)$ \\
\hline 8246/3: Neuroendocrine carcinoma, NOS & $6(6)$ \\
\hline 8280/3: Acidophil carcinoma & $3(3)$ \\
\hline
\end{tabular}

Table 2. Histology and behavior of primary pituitary tumors based on ICD-O-3. NOS Not otherwise specified. ${ }^{a}$ Included chromophobe adenoma (8270/0), acidophil adenoma (8280/0), basophil adenoma (8300/0), monomorphic adenoma (8146/0), mixed acidophil-basophil adenoma (8281/0), mixed cell adenoma $(8323 / 0)$, and macrofollicular adenoma $(8334 / 0)$.

\begin{tabular}{|l|l|l|l|l|}
\hline Variables & Typical adenomas & UPAs & PCs & $P$ \\
\hline Surgery & $21,258(45)$ & $63(57)$ & $19(49)$ & $0.015^{*}$ \\
\hline Yes & $25,772(55)$ & $48(43)$ & $20(51)$ & \\
\hline None/unknown & \multicolumn{5}{l}{} & $<0.001^{\star *}$ \\
\hline Radiation & $1647(4)$ & $21(19)$ & $8(21)$ & \\
\hline Yes & $45,383(96)$ & $90(81)$ & $31(79)$ & \\
\hline None/unknown & & & \\
\hline
\end{tabular}

Table 3. Treatment strategies of patients with primary pituitary tumors. UPAs Uncertain behavior pituitary adenomas, $P C s$ Pituitary carcinomas. Data presented as $\mathrm{n}(\%)$ or just numbers. ${ }^{\star} P$ value for difference between UPAs and typical adenomas. ${ }^{*} P$ value for difference between UPAs + PCs and typical adenomas.

$\mathbf{a}$

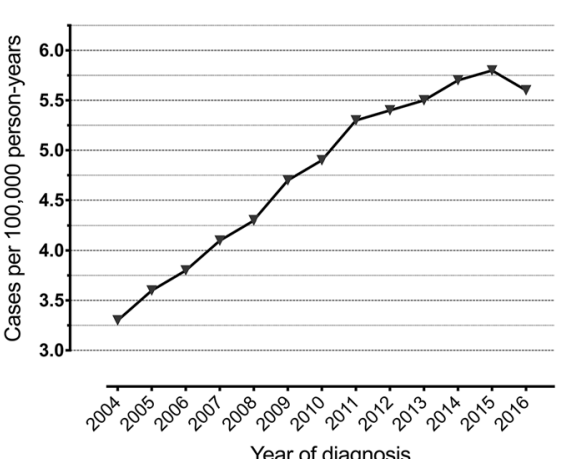

b
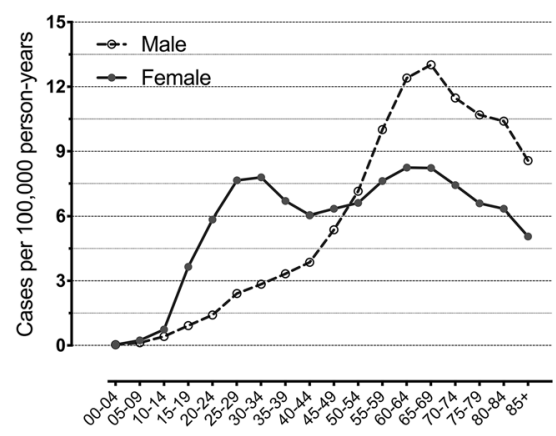

Age groups (years)
C Incidence Rate by Age Groups and Treatment
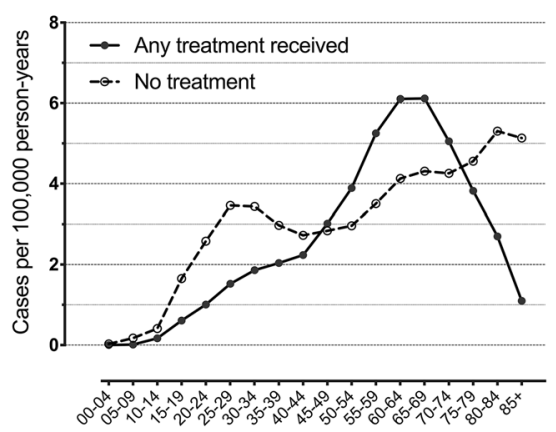

Age groups (years)

Figure 1. Standardized incidence rate of primary pituitary adenoma by (a) year of diagnosis, (b) age/sex groups and (c) age/treatment groups. Reference population is the general US population or the population in corresponding groups.

experienced worse survival, while the extent of surgical resection was not associated with overall survival in the multivariate analysis (Table 4). 
a

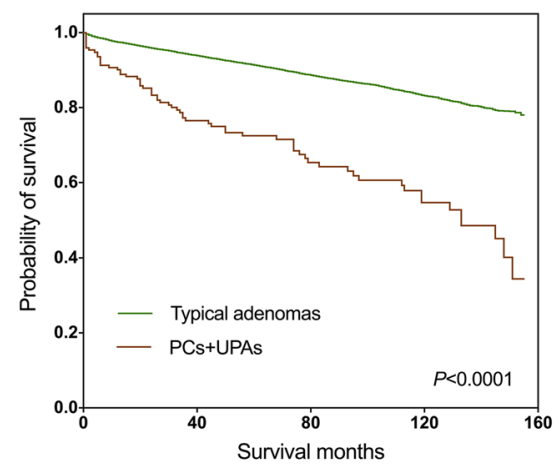

b

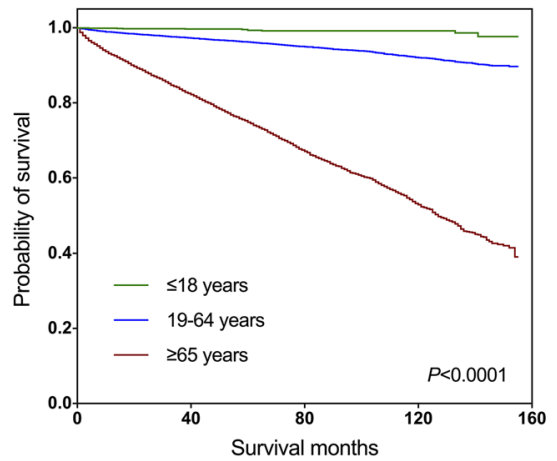

C

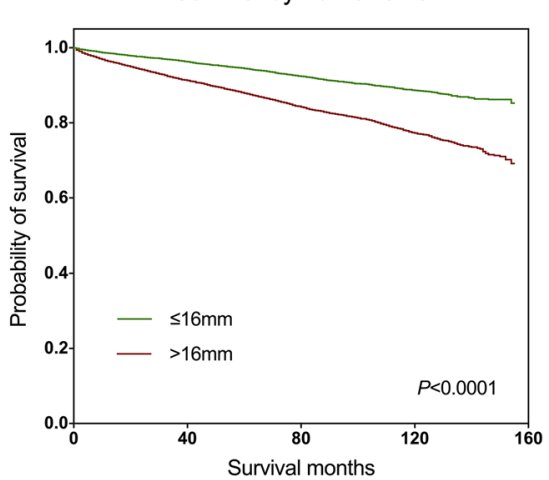

Figure 2. Kaplan-Meier survival curves of all primary pituitary tumors stratified by (a) subtypes, (b) age groups and (c) tumor size. UPAs Uncertain behavior pituitary adenomas, PCs Pituitary carcinomas.

\begin{tabular}{|c|c|c|c|c|}
\hline Variables $^{\mathrm{a}}$ & HR (95\%CI) & $P$ & OR $(95 \% \mathrm{CI})$ & $P$ \\
\hline \multicolumn{5}{|l|}{ Age groups } \\
\hline$\leq 18$ years & Reference & & Reference & \\
\hline 19-64 years & $7.883(4.346-14.300)$ & $<0.001$ & $7.652(4.205-13.928)$ & $<0.001$ \\
\hline$\geq 65$ years & $52.266(28.785-94.903)$ & $<0.001$ & $59.264(32.507-108.042)$ & $<0.001$ \\
\hline \multicolumn{5}{|l|}{ Gender } \\
\hline Female & Reference & & Reference & \\
\hline Male & $1.275(1.203-1.352)$ & $<0.001$ & $1.326(1.241-1.418)$ & $<0.001$ \\
\hline \multicolumn{5}{|l|}{ Race } \\
\hline White & Reference & & Reference & \\
\hline Black & $1.269(1.185-1.360)$ & $<0.001$ & $1.339(1.235-1.452)$ & $<0.001$ \\
\hline Others & $0.689(0.615-0.771)$ & $<0.001$ & $0.627(0.554-0.710)$ & $<0.001$ \\
\hline \multicolumn{5}{|l|}{ Marital status } \\
\hline Unmarried & Reference & & Reference & \\
\hline Married & $0.987(0.910-1.071)$ & 0.760 & $1.078(0.985-1.180)$ & 0.101 \\
\hline \multicolumn{5}{|l|}{ Insurance } \\
\hline Insured & Reference & & Reference & \\
\hline Uninsured & $1.259(1.029-1.541)$ & 0.025 & $1.246(1.004-1.547)$ & 0.046 \\
\hline \multicolumn{5}{|l|}{ Tumor size } \\
\hline$\leq 16 \mathrm{~mm}$ & Reference & & Reference & \\
\hline$>16 \mathrm{~mm}$ & $1.678(1.557-1.808)$ & $<0.001$ & $1.801(1.656-1.960)$ & $<0.001$ \\
\hline \multicolumn{5}{|l|}{ Extent of resection } \\
\hline GTR & Reference & & Reference & \\
\hline STR & $0.986(0.874-1.113)$ & 0.823 & $0.884(0.770-1.014)$ & 0.079 \\
\hline \multicolumn{5}{|l|}{ Radiation } \\
\hline No/unknown & Reference & & Reference & \\
\hline Yes & $1.186(1.047-1.345)$ & 0.008 & $1.404(1.207-1.634)$ & $<0.001$ \\
\hline \multicolumn{5}{|l|}{ Subtypes } \\
\hline Typical adenomas & Reference & & Reference & \\
\hline UPAs & $1.848(1.303-2.620)$ & 0.001 & $2.721(1.696-4.365)$ & $<0.001$ \\
\hline PCs & $2.065(1.026-4.160)$ & 0.042 & $1.876(0.786-4.480)$ & 0.057 \\
\hline
\end{tabular}

Table 4. Results of multivariate regression for demographic and clinical variables associated with overall survival. HR Hazard ratio, OR Odds ratio, GTR Gross total resection, STR Subtotal resection, UPAs Uncertain behavior pituitary adenomas, PCs Pituitary carcinomas. ${ }^{a}$ Unknown data were removed from regression model due to heterogeneity. 


\section{Discussion}

The SEER database is widely recognized to be among the most reliable resources in reporting epidemiologic features and survival data for various neoplasms. In this retrospective population-based study, we attempted to address the available information regarding primary pituitary tumors and placed insight into the incidence rate, demographic characteristics, and survival outcome of this group of tumors.

Prior cross-sectional observation studies carried outside the United States identified a standardized incidence rate ranging from 0.6 to 7.4 cases per 100,000 inhabitants per year ${ }^{6,8-10,16,17}$. For the massive population included in the SEER database, an incidence rate of 4.8 per 100,000 person-years that we described is highly generalizable and might be more reflective of the population experience. Additionally, we noticed a bimodal age-related differential distribution in female patients with an evaluated incidence around the third decade of lifespan. This finding is accordant with McDowell et al. ${ }^{18}$ who discovered a higher incidence rate in females during early life and with several other studies which characterized a higher incidence in younger female patients with prolactinomas ${ }^{8,19,20}$. One possible explanation is that clinical manifestations such as infertility, amenorrhea, and galactorrhea would be more pronounced in women of childbearing age, which would increase diagnostic rate $e^{6,8,9}$. For prolactinoma being the most frequent tumor subtype reported in previous literature, it is not surprising that females have a higher overall incidence rate than men. In clinical settings, microprolactinomas are approximately twofold more frequent than macroadenomas ${ }^{21,22}$, which contribute to the majority of incidence rate in female patients during the fertile period, not to mention that the true prevalence of microprolactinomas may be underestimated because many suspected tumors are unreported by primary physicians ${ }^{9}$. The effects of prolactinomas on mortality remain controversial, several studies concluded that hyperprolactinemia-related metabolic imbalance is associated with impaired overall survival ${ }^{23-25}$, while others argued that prolactinomas or hyperprolactinemia would not increase mortality rate ${ }^{26,27}$. The hormone-secretion data was, however, missing in the SEER dataset, so we were unable to interpret the specific incidence and survival outcome of each hormonal subtype. Moreover, most patients were vaguely classified as pituitary adenomas in the histopathological designation, which precluded us from inferring the actual prevalence of prolactinoma.

Consistent with previous reports, a constantly increasing annual prevalence has been well characterized in our study, with a nearly doubling of the incidence rate in 2015 compared to 2004 . The rising incidence might be related to the significant advancements in neuroimaging, a higher incidentally discovered rate or the increased awareness of pituitary diseases among physicians. Of note, there has been debate about whether the real incidence of pituitary tumor is rising or just the incidentally discovered rate. Raappana et al. ${ }^{8}$ demonstrated in their 16-year period study in Northern Finland that the increase in the incidence rate was caused by incidentaloma rather than symptomatic pituitary adenoma, while Radhakrishnan et al. ${ }^{28}$ discovered that the incidence of symptomatic pituitary tumors also remarkably risen in the Minnesota population. We also found that treatment modalities varied by age group and patients aged $>74$ years may not receive any treatment. Since older patients are more vulnerable to surgery-related complications such as hypopituitarism, cerebrospinal fluid leaks, and diabetes insipidus ${ }^{29,30}$, it is understandable that a wait-and-see protocol was more preferable in some cases. Moreover, the first peak of incidence rate in females coincided with the non-treatment group, a possible explanation being that the SEER database does not include data on conventional drug treatment, which would lead to a higher untreated rate.

One year after the study period of current research, the 4th edition of the World Health Organization classification of endocrine tumors has recommended several pathological changes of anterior pituitary gland tumors $^{31-33}$. A major change is the abandonment of hormone-producing adenomas and the subsequent adoption of adenohypophyseal cell lineage as the main principle for classifying pituitary endocrine tumors. This implies that the histological classification based on ICD-O-3 in Table 2 seems to be outdated in the context of new classification. Another notable change is the histological grading of pituitary tumors, which eliminated the controversial term "atypical pituitary adenomas". And since then, the transitory stage from typically benign adenoma to carcinoma is very vague and shares uneven definition criteria. Current clinical practice in defining aggressive pituitary adenomas (APAs) had been proposed by several groups of experts ${ }^{34,35}$, which is based on the resistance to medical treatments and multiple recurrences despite standard therapies (including surgery, radiotherapy, and chemotherapy). We identified 111 UPAs and 39 PCs in our research and the constituent ratio was consistent with the European Society of Endocrinology's survey in 2016, which reported 125 APAs and 40 PCs across 17 European countries ${ }^{36}$. PCs are extremely rare types of neoplasms. We reported a prevalence of $0.08 \%$ among the entire cohort, which is slightly lower than the $0.1-0.2 \%$ found in the existing literature ${ }^{37-42}$. Anthony claimed that $75 \%$ of PC cases are diagnosed at autopsy ${ }^{43}$, a lack of autopsy data in our cohort would be the possible explanation for the low prevalence of PCs. Sex predilection is not well established in the literature in terms of PCs, yet, as the two most common types of carcinoma, malignant prolactinoma and corticotropic carcinoma are more likely to be found in $\operatorname{men}^{38,44,45}$, which is consistent with the male predominance in our study.

Because of the benign histopathological nature of primary pituitary tumors, the prognosis is excellent as far as overall survival. Nevertheless, pituitary tumors are associated with a substantially decreased overall survival, with a mortality rate two to fivefold higher than that of the general population ${ }^{4,16,46,47}$. The main causes of elevated mortality may be attributed to cardio/cerebrovascular accidents, respiratory diseases, infections, and secondary malignancies ${ }^{46,48}$. These phenomena are speculated to be related to excessive hormone secretion (especially of growth hormone and corticotropic hormone $)^{2}$, hypopituitarism ${ }^{49,50}$, hormone replacement therapy ${ }^{51-53}$, and therapeutic intervention, such as surgery and irradiation ${ }^{54}$.

Not surprisingly, in our study, the Kaplan-Meier survival curves depicted that patients with younger age, smaller tumor size or those diagnosed as typical adenoma experienced improved overall survival. This result was further verified by multivariate regression analysis when we ruled out the effects of relevant covariates. Consistent with several studies ${ }^{55-57}$, we found that female patients displayed a superior survival over men, while some other studies yielded opposite results ${ }^{16,58}$. Still, the gender-related mortality and underlying reasons remain 
obscure and future matches control studies are warranted to further elucidate this issue. Of interest, the other race patients (mostly Asiatic ethnicity) experienced prolonged overall survival than black/white patients. No existing literature has successfully addressed the relationship between ethnicity and mortality with regard to pituitary tumors. Even though a number of studies have attributed race-related mortality to economic and treatment inequalities in specific disease $\mathrm{e}^{59-61}$, such disparities in pituitary adenomas merit future investigations. Surgical resection, especially endonasal transsphenoidal surgery, is the current standard of care for primary pituitary tumors except for prolactinoma, which is usually treated with dopamine agonists. When adjusted for sex, age, race, subtypes, and other relevant covariates in the multivariate regression models, GTR, however, still did not yield an improved survival outcome over STR. Ntali et al. ${ }^{46}$ found similar results in their systemic analysis of 546 non-functioning pituitary adenoma cases when they showed that neither extent of removal nor repeated surgery predicted long-term mortality. We also noticed that the patients treated with irradiation tended to have worse survival outcomes either in the entire cohort or in the UPA + PC groups. Hansen et al. ${ }^{62}$ found similar results in their study that included 117 invasive adenomas/pituitary carcinomas in the SEER program from 1973 to 2008. They described no survival advantage for radiation therapy in treating adenomas and speculated that patients with more aggressive tumors would be preferentially offered irradiation. However, because of the biases associated with the unmeasured reasons for receiving or not receiving radiation therapy, any conclusions about its efficacy should be made with caution.

Prior SEER dataset-based studies regarding pituitary tumors focused either on typical adenoma (benign behavior) or on malignant behavior tumors (invasive adenoma and pituitary carcinoma) without jointly analyzing standardized incidence rate and mortality ${ }^{18,62,63}$. The present study found that the annual incidence is increasing and revealed additional factors that associated with overall survival in all histology types with a longer surveillance period. The large sample size of primary pituitary tumors, consensus protocol, and long-term surveillance are the strength of our study; however, our findings should be considered in the context of their limitations. First, the SEER program is subject to the potential for miscoding, which could lead to inaccurate demographic information. Second, the analysis was limited by the available data in the SEER database. As an important topic of benign tumors, recurrence and subsequent treatment data were not provided and therefore prevented us from providing a disease-free survival analysis. Additionally, the hormone secretion function was not provided, as such, the incidence rate and survival of hormonal subtypes could not be calculated. Third, a high proportion of non-operated patients and the resultant low pathological diagnosis rate could contribute to misclassification of pituitary tumors. Finally, information about the quality of life, mental health, and medical comorbidities was not provided, which was critical to assess the burden of the disease.

\section{Conclusion}

In this retrospective SEER-based study, we provide a reliable estimate on the overall standardized incidence rate of patients with primary pituitary tumors and confirm that the annual incidence rate is increasing. More than $80 \%$ of the patients survived 10 years and younger age at diagnosis, smaller tumor size, and typical adenoma are associated with prolonged overall survival. Other demographics, such as gender and race, and their association with worse survival outcomes remain to be elucidated in future clinical trials. Although our study provides a comprehensive overview of the incidence, demographics, and survival of patients with pituitary adenoma, the inferential findings should be constrained within the inherent limitations of the SEER database.

\section{Data availability}

All data are freely available in the SEER datasets.

Received: 3 May 2021; Accepted: 9 July 2021

Published online: 26 July 2021

\section{References}

1. Mete, O., Cintosun, A., Pressman, I. \& Asa, S. L. Epidemiology and biomarker profile of pituitary adenohypophysial tumors. Mod. Pathol. 31, 900-909. https://doi.org/10.1038/s41379-018-0016-8 (2018).

2. Mehta, G. U. \& Lonser, R. R. Management of hormone-secreting pituitary adenomas. Neuro Oncol. 19, 762-773. https://doi.org/ 10.1093/neuonc/now130 (2017).

3. Sughrue, M. E., Chang, E. F., Gabriel, R. A., Aghi, M. K. \& Blevins, L. S. Excess mortality for patients with residual disease following resection of pituitary adenomas. Pituitary 14, 276-283. https://doi.org/10.1007/s11102-011-0308-1 (2011).

4. Clayton, R. N., Raskauskiene, D., Reulen, R. C. \& Jones, P. W. Mortality and morbidity in Cushing's disease over 50 years in Stokeon-Trent, UK: audit and meta-analysis of literature. J. Clin. Endocrinol. Metab. 96, 632-642. https://doi.org/10.1210/jc.2010-1942 (2011).

5. Tampourlou, M., Fountas, A., Ntali, G. \& Karavitaki, N. Mortality in patients with non-functioning pituitary adenoma. Pituitary 21, 203-207. https://doi.org/10.1007/s11102-018-0863-9 (2018).

6. Gruppetta, M., Mercieca, C. \& Vassallo, J. Prevalence and incidence of pituitary adenomas: a population based study in Malta. Pituitary 16, 545-553. https://doi.org/10.1007/s11102-012-0454-0 (2013).

7. Fernandez, A., Karavitaki, N. \& Wass, J. A. Prevalence of pituitary adenomas: a community-based, cross-sectional study in Banbury (Oxfordshire, UK). Clin. Endocrinol. (Oxf.) 72, 377-382. https://doi.org/10.1111/j.1365-2265.2009.03667.x (2010).

8. Raappana, A., Koivukangas, J., Ebeling, T. \& Pirila, T. Incidence of pituitary adenomas in Northern Finland in 1992-2007. J. Clin. Endocrinol. Metab. 95, 4268-4275. https://doi.org/10.1210/jc.2010-0537 (2010).

9. Tjornstrand, A. et al. The incidence rate of pituitary adenomas in western Sweden for the period 2001-2011. Eur. J. Endocrinol. 171, 519-526. https://doi.org/10.1530/EJE-14-0144 (2014).

10. Agustsson, T. T. et al. The epidemiology of pituitary adenomas in Iceland, 1955-2012: A nationwide population-based study. Eur. J. Endocrinol. 173, 655-664. https://doi.org/10.1530/EJE-15-0189 (2015).

11. NIH. National Cancer Institute SEER Training Modules. Non-malignant Brain Tumors. https://training.seer.cancer.gov/brain/ non-malignant/. Accessed 10 Nov 2020. 
12. NIH. National Cancer Institute SEER ${ }^{\star}$ Stat Databases: November 2019 Submission. https://seer.cancer.gov/data-software/docum entation/seerstat/nov2019/. Accessed 15 July 2020.

13. NIH. National Cancer Institute SEER Incidence Database, How to Request Access to SEER Data. https://seer.cancer.gov/data/ access.html. Accessed 15 July 2020.

14. CS. Collaborative Stage Version 2 Schema List v.02.05.00. IntracranialGland. CS Mets at DX. http://web2.facs.org/cstage0205/intra cranialgland/IntracranialGland_hpa.html. Accessed 21 Nov 2020.

15. NIH. National Cancer Institute SEER datasets. U.S. Population Data-1969-2019. https://seer.cancer.gov/popdata/. Accessed 9 Dec 2020.

16. Nilsson, B., Gustavasson-Kadaka, E., Bengtsson, B. A. \& Jonsson, B. Pituitary adenomas in Sweden between 1958 and 1991: Incidence, survival, and mortality. J. Clin. Endocrinol. Metab. 85, 1420-1425. https://doi.org/10.1210/jcem.85.4.6498 (2000).

17. Day, P. F. et al. Incidence and prevalence of clinically relevant pituitary adenomas: Retrospective cohort study in a Health Management Organization in Buenos Aires, Argentina. Arch. Endocrinol. Metab. 60, 554-561. https://doi.org/10.1590/2359-3997000000 195 (2016)

18. McDowell, B. D. et al. Demographic differences in incidence for pituitary adenoma. Pituitary 14, 23-30. https://doi.org/10.1007/ s11102-010-0253-4 (2011).

19. Chanson, P. \& Maiter, D. The epidemiology, diagnosis and treatment of Prolactinomas: The old and the new. Best Pract. Res. Clin. Endocrinol. Metab. 33, 101290. https://doi.org/10.1016/j.beem.2019.101290 (2019).

20. Vroonen, L., Daly, A. F. \& Beckers, A. Epidemiology and management challenges in prolactinomas. Neuroendocrinology 109, 20-27. https://doi.org/10.1159/000497746 (2019).

21. Huang, W. \& Molitch, M. E. Pituitary tumors in pregnancy. Endocrinol. Metab. Clin. N. Am. 48, 569-581. https://doi.org/10.1016/j. ecl.2019.05.004 (2019).

22. Colao, A. Pituitary tumours: The prolactinoma. Best Pract. Res. Clin. Endocrinol. Metab. 23, 575-596. https://doi.org/10.1016/j. beem.2009.05.003 (2009).

23. Haring, R. et al. Positive association of serum prolactin concentrations with all-cause and cardiovascular mortality. Eur. Heart J. 35, 1215-1221. https://doi.org/10.1093/eurheartj/ehs233 (2014).

24. Krogh, J., Selmer, C., Torp-Pedersen, C., Gislason, G. H. \& Kistorp, C. Hyperprolactinemia and the association with all-cause mortality and cardiovascular mortality. Horm. Metab. Res. 49, 411-417. https://doi.org/10.1055/s-0043-107243 (2017).

25. Andersen, M. \& Glintborg, D. Metabolic syndrome in hyperprolactinemia. Front. Horm. Res. 49, 29-47. https://doi.org/10.1159/ 000486000 (2018).

26. Hoffmann, A., Adelmann, S., Lohle, K., Claviez, A. \& Muller, H. L. Pediatric prolactinoma: Initial presentation, treatment, and long-term prognosis. Eur. J. Pediatr. 177, 125-132. https://doi.org/10.1007/s00431-017-3042-5 (2018).

27. Soto-Pedre, E., Newey, P. J., Bevan, J. S. \& Leese, G. P. Morbidity and mortality in patients with hyperprolactinaemia: The PROLEARS study. Endocr. Connect. 6, 580-588. https://doi.org/10.1530/EC-17-0171 (2017).

28. Radhakrishnan, K. et al. The trends in incidence of primary brain tumors in the population of Rochester, Minnesota. Ann. Neurol. 37, 67-73. https://doi.org/10.1002/ana.410370113 (1995).

29. Tardivo, V. et al. Surgical management of pituitary adenomas: Does age matter?. Pituitary 23, 92-102. https://doi.org/10.1007/ s11102-019-01014-1 (2020).

30. Lobatto, D. J. et al. Preoperative risk factors for postoperative complications in endoscopic pituitary surgery: A systematic review. Pituitary 21, 84-97. https://doi.org/10.1007/s11102-017-0839-1 (2018).

31. Lopes, M. B. S. The 2017 World Health Organization classification of tumors of the pituitary gland: A summary. Acta Neuropathol 134, 521-535. https://doi.org/10.1007/s00401-017-1769-8 (2017).

32. Mete, O. \& Lopes, M. B. Overview of the 2017 WHO classification of pituitary tumors. Endocr. Pathol. 28, 228-243. https://doi. org/10.1007/s12022-017-9498-z (2017).

33. Inoshita, N. \& Nishioka, H. The 2017 WHO classification of pituitary adenoma: Overview and comments. Brain Tumor Pathol. 35, 51-56. https://doi.org/10.1007/s10014-018-0314-3 (2018).

34. Sav, A. et al. Invasive, atypical and aggressive pituitary adenomas and carcinomas. Endocrinol. Metab. Clin. N. Am. 44, 99-104. https://doi.org/10.1016/j.ecl.2014.10.008 (2015).

35. Raverot, G. et al. European Society of Endocrinology Clinical Practice Guidelines for the management of aggressive pituitary tumours and carcinomas. Eur. J. Endocrinol. 178, G1-G24. https://doi.org/10.1530/EJE-17-0796 (2018).

36. McCormack, A. et al. Treatment of aggressive pituitary tumours and carcinomas: results of a European Society of Endocrinology (ESE) survey 2016. Eur. J. Endocrinol. 178, 265-276. https://doi.org/10.1530/EJE-17-0933 (2018).

37. Ragel, B. T. \& Couldwell, W. T. Pituitary carcinoma: A review of the literature. Neurosurg. Focus 16, E7. https://doi.org/10.3171/ foc.2004.16.4.8 (2004).

38. Yoo, F., Kuan, E. C., Heaney, A. P., Bergsneider, M. \& Wang, M. B. Corticotrophic pituitary carcinoma with cervical metastases: Case series and literature review. Pituitary 21, 290-301. https://doi.org/10.1007/s11102-018-0872-8 (2018).

39. Park, K. S., Hwang, J. H., Hwang, S. K., Kim, S. \& Park, S. H. Pituitary carcinoma with fourth ventricle metastasis: treatment by excision and Gamma-knife radiosurgery. Pituitary 17, 514-518. https://doi.org/10.1007/s11102-013-0537-6 (2014).

40. Kamiya-Matsuoka, C. et al. Radiotherapy with concurrent temozolomide for the management of extraneural metastases in pituitary carcinoma. Pituitary 19, 415-421. https://doi.org/10.1007/s11102-016-0721-6 (2016).

41. Bengtsson, D. et al. Long-term outcome and MGMT as a predictive marker in 24 patients with atypical pituitary adenomas and pituitary carcinomas given treatment with temozolomide. J. Clin. Endocrinol. Metab. 100, 1689-1698. https://doi.org/10.1210/jc. 2014-4350 (2015).

42. Dworakowska, D. \& Grossman, A. B. Aggressive and malignant pituitary tumours: State-of-the-art. Endocr. Relat. Cancer 25, R559-R575. https://doi.org/10.1530/ERC-18-0228 (2018).

43. Heaney, A. P. Clinical review: Pituitary carcinoma: Difficult diagnosis and treatment. J. Clin. Endocrinol. Metab. 96, 3649-3660. https://doi.org/10.1210/jc.2011-2031 (2011).

44. Hong, A. R., Yoon, J. H., Kim, H. K. \& Kang, H. C. Malignant prolactinoma with liver metastases masquerading as metastatic gastrointestinal stromal tumor: A case report and literature review. Front. Endocrinol. (Lausanne) 11, 451. https://doi.org/10.3389/ fendo.2020.00451 (2020).

45. Lamas, C. et al. Malignant prolactinoma with multiple bone and pulmonary metastases. Case report. J. Neurosurg. 101, 116-121. https://doi.org/10.3171/ped.2004.101.2.0116 (2004).

46. Ntali, G. et al. Mortality in patients with non-functioning pituitary adenoma is increased: Systematic analysis of 546 cases with long follow-up. Eur. J. Endocrinol. 174, 137-145. https://doi.org/10.1530/EJE-15-0967 (2016).

47. Javanmard, P., Duan, D. \& Geer, E. B. Mortality in patients with endogenous Cushing's syndrome. Endocrinol. Metab. Clin. N. Am. 47, 313-333. https://doi.org/10.1016/j.ecl.2018.02.005 (2018).

48. Sattler, M. G. et al. The incidence of second tumours and mortality in pituitary adenoma patients treated with postoperative radiotherapy versus surgery alone. Radiother. Oncol. 104, 125-130. https://doi.org/10.1016/j.radonc.2012.04.024 (2012).

49. O'Reilly, M. W. et al. ACTH and gonadotropin deficiencies predict mortality in patients treated for nonfunctioning pituitary adenoma: Long-term follow-up of 519 patients in two large European centres. Clin. Endocrinol. (Oxf.) 85, 748-756. https://doi. org/10.1111/cen.13141 (2016). 
50. Lindholm, J. et al. Hypopituitarism and mortality in pituitary adenoma. Clin. Endocrinol. (Oxf.) 65, 51-58. https://doi.org/10. $1111 / j .1365-2265.2006 .02545 . x(2006)$.

51. Hammarstrand, C. et al. Higher glucocorticoid replacement doses are associated with increased mortality in patients with pituitary adenoma. Eur. J. Endocrinol. 177, 251-256. https://doi.org/10.1530/EJE-17-0340 (2017).

52. Zueger, T. et al. Glucocorticoid replacement and mortality in patients with nonfunctioning pituitary adenoma. J. Clin. Endocrinol. Metab. 97, E1938-1942. https://doi.org/10.1210/jc.2012-2432 (2012).

53. Postma, M. R. et al. Postoperative use of somatostatin analogs and mortality in patients with acromegaly. Eur. J. Endocrinol. 180, 1-9. https://doi.org/10.1530/EJE-18-0166 (2019).

54. Chang, E. F. et al. Long-term recurrence and mortality after surgery and adjuvant radiotherapy for nonfunctional pituitary adenomas. J. Neurosurg. 108, 736-745. https://doi.org/10.3171/JNS/2008/108/4/0736 (2008).

55. Nielsen, E. H. et al. Nonfunctioning pituitary adenoma: Incidence, causes of death and quality of life in relation to pituitary function. Pituitary 10, 67-73. https://doi.org/10.1007/s11102-007-0018-x (2007).

56. Kauppinen-Makelin, R. et al. A nationwide survey of mortality in acromegaly. J. Clin. Endocrinol. Metab. 90, 4081-4086. https:// doi.org/10.1210/jc.2004-1381 (2005).

57. Lambert, J. K. et al. Predictors of mortality and long-term outcomes in treated Cushing's disease: A study of 346 patients. J. Clin. Endocrinol. Metab. 98, 1022-1030. https://doi.org/10.1210/jc.2012-2893 (2013).

58. Olsson, D. S. et al. Excess mortality in women and young adults with nonfunctioning pituitary adenoma: A Swedish nationwide study. J. Clin. Endocrinol. Metab. 100, 2651-2658. https://doi.org/10.1210/jc.2015-1475 (2015).

59. Khan, S. Q. et al. Infant and youth mortality trends by race/ethnicity and cause of death in the United States. JAMA Pediatr. 172, e183317. https://doi.org/10.1001/jamapediatrics.2018.3317 (2018).

60. Mode, N. A., Evans, M. K. \& Zonderman, A. B. Race, Neighborhood economic status, income inequality and mortality. PLoS ONE 11, e0154535. https://doi.org/10.1371/journal.pone.0154535 (2016).

61. Cosby, A. G. et al. Growth and persistence of place-based mortality in the United States: The rural mortality penalty. Am. J. Public Health 109, 155-162. https://doi.org/10.2105/AJPH.2018.304787 (2019).

62. Hansen, T. M. et al. Invasive adenoma and pituitary carcinoma: A SEER database analysis. Neurosurg. Rev. 37, 279-285. https:// doi.org/10.1007/s10143-014-0525-y (2014).

63. Aharon-Hananel, G., Percik, R., Badarna, M., Uri, I. \& Tirosh, A. Lower all-cause mortality rates in patients harboring pituitary carcinoma following the introduction of temozolomide. Endocrine 65, 393-398. https://doi.org/10.1007/s12020-019-01996-9 (2019).

\section{Acknowledgements}

This is a retrospective study based on the SEER program-an open-access database and the contents are the author's sole responsibility. The authors sincerely thank Prof. Guanjian Liu (Department of Evidence-Based Medicine and Clinical Epidemiology Center, West China School of Medicine, Sichuan University) for reviewing our statistical analyses.

\section{Author contributions}

Study concept and design: C.C., Y.H., S.J., P.Z.Z.; Data access and collection: C.C., Y.H.; Data analysis and illustration editing: C.C., Y.H., L.L., S.L.Y., Y.Y.; Manuscript drafting: C.C., Y.H., L.L.; Supervised the study and revised the manuscript for intellectual content: S.J., P.Z.Z.; Final approval of the manuscript: All authors.

\section{Funding}

This research was financially supported by Foundation of Science and Technology Department of Sichuan province (2019YFS0398) and Post-Doctor Research Project of Sichuan University (2020HXBH157).

\section{Competing interests}

The authors declare no competing interests.

\section{Additional information}

Correspondence and requests for materials should be addressed to P.Z.

Reprints and permissions information is available at www.nature.com/reprints.

Publisher's note Springer Nature remains neutral with regard to jurisdictional claims in published maps and institutional affiliations.

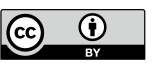

Open Access This article is licensed under a Creative Commons Attribution 4.0 International License, which permits use, sharing, adaptation, distribution and reproduction in any medium or format, as long as you give appropriate credit to the original author(s) and the source, provide a link to the Creative Commons licence, and indicate if changes were made. The images or other third party material in this article are included in the article's Creative Commons licence, unless indicated otherwise in a credit line to the material. If material is not included in the article's Creative Commons licence and your intended use is not permitted by statutory regulation or exceeds the permitted use, you will need to obtain permission directly from the copyright holder. To view a copy of this licence, visit http://creativecommons.org/licenses/by/4.0/.

(C) The Author(s) 2021 